\title{
AUTORÍA Y OTREDADES EN LOS DIARIOS DE VIAJE ALREDEDOR DEL MUNDO DE FRANCISCO ECHAURREN*
}

\section{AUTHORSHIP AND OTHERNESS IN FRANCISCO ECHAURREN'S DIARIES FROM HIS VOYAGE AROUND THE WORLD}

\author{
JOSÉ DÍAZ-DIEGO**, FRANCISCO JAVIER MEDIANERO SOTO***, \\ JOSÉ MANUEL ZAVALA CEPEDA****
}

Resumen: Los diarios de viaje de Francisco Echaurren (1852-1857) son los más antiguos que se conservan hoy de un viajero chileno alrededor del mundo. Para profundizar en los mismos, exponemos el perfil social y político del autor, la estructura y estilo literario de los diarios, y los vínculos entre la autoría y la representación de otredades como las élites locales, los criados y los guías. Escritos para recordar el viaje y no para ser publicados, los cuadernos se caracterizan por la franqueza de su intimidad. Concluimos subrayando la presencia en los textos de valores modernos de predilección por la aventura, el exotismo y el protagonismo del sujeto, así como de estrategias escriturales que marcan un clasismo constante en la construcción del otro.

Palabras Clave: Francisco Echaurren, Chile, diarios de viaje, élite, siglo XIX.

Aвstract: Francisco Echaurren's diaries from his voyage around the world (18521857) are the oldest extant example of this genre from a Chilean traveler. In order to deepen our understanding of this work, we explore the social and political profile of the author, the diaries' structure and literary style, and the links between authorship and the representation of otherness through Echaurren's descriptions of local elites,

* Este artículo es parte de los resultados de investigación del proyecto VIP44/2017 sobre los diarios de viaje de Francisco Echaurren, financiado por la Universidad Católica de Temuco (Chile). Querríamos mostrar nuestro agradecimiento a Luis Martínez, Pedro González, María Mena, Miguel Carrasco y José Huenupi por las facilidades brindadas durante el trabajo archivístico y a Angélica Cardemil y a Armando Luza por su apoyo en las labores de digitalización de los manuscritos. Finalmente, nos gustaría agradecer los comentarios y sugerencias de los pares evaluadores. Indicar además que la ortografía original de Francisco Echaurren, que sigue las indicaciones ortográficas de Andrés Bello, ha sido adaptada aquí a la norma ortográfica actual del castellano moderno.

** Doctor en Estudios del Desarrollo. Profesor Contratado Doctor, Departamento de Antropología Social, Psicología Básica y Salud Pública, Universidad Pablo de Olavide de Sevilla, España. Correo electrónico: jdiadie@upo.es

*** Doctor en Arqueología. Profesor Asistente, Departamento de Antropología, Universidad Católica de Temuco, Chile. Correo electrónico: fmedianero@uct.cl

**** Doctor en Antropología. Profesor Asociado, Departamento de Ciencias Históricas, Universidad de Chile, Santiago, Chile. Correo electrónico: josezavala@uchile.cl 
servants, and guides. The diaries are characterized by their candor and intimacy, as they were written as a personal record of the journey but not meant to be published. We conclude by emphasizing the work's embodiment of modern values, such as a predilection for adventure, exoticism and the subject's centrality, as well as the scriptural strategies that reveal the author's class bias in the construction of otherness.

KEYwORDs: Francisco Echaurren, Chile, travel diaries, elite, XIX century.

Recibido: 12.04.19. Aceptado: 25.09.19.

\section{INTRODUCCIÓN}

$\mathrm{E}$ 14 De noviembre de 2016, la Dirección de Bibliotecas, Archivos y Museos de Chile adquirió una colección privada de 11 volúmenes con cuadernos de tesorería y 153 libros, álbumes y cartas familiares (DIBAM, 2016). Entre los manuscritos se encuentran los "libros de anotaciones de viajes de Francisco Echaurren". Dichos libros de anotaciones corresponden a cuatro diarios manuscritos por Francisco Echaurren García-Huidobro $(1853,1854 a, 1854 b$ y 1855$)$ con notas sobre su viaje alrededor del mundo. Las anotaciones abarcan desde el 16 de diciembre de 1853 al 18 de diciembre de 1855, lo que supone el registro de dos de sus cuatro años largos de viaje, que inició en enero de 1852, luego de participar y perder en la revolución de 1851, y finalizó el 31 de agosto de 1857 con su arribo a Valparaíso.

Los diarios de viaje de Francisco Echaurren han estado fuera de los circuitos académicos hasta ahora. Ello explica que cronologías de viajeros chilenos del siglo XIX, como la del portal "Memoria Chilena" de la Biblioteca Nacional de Chile no lo nombren, como tampoco destacados historiadores y literatos que han abordado el estudio de la élite y los intelectuales, hijos ya de la República, que comenzaron a viajar recurrentemente a Europa y Norteamérica, e incluso a Tierra Santa, durante la segunda mitad del siglo XIX (Brintrup, 1992; Pinto, 2008; Maino, 2014 y Ramírez, 2014). Se trata por tanto de un viajero de cuyos trayectos no había referencias autobiográficas y las historiográficas son escasísimas.

Desde un punto de vista histórico y antropológico, los textos de Echaurren nos interesan en tanto producto cultural y, en concreto, en tanto piezas escriturales que, en primera persona, nos permiten incursionar por los mundos de intereses, motivaciones, acciones, disposiciones y emociones de uno de los miembros de aquella primera generación de republicanos que, llamado por sus apellidos a asumir más tarde altas responsabilidades de gestión pública, transformaría su exilio en un viaje de enriquecimiento 
personal a lo ancho del globo. En dicho periplo, redactaría para su recuerdo notas que se insertan en la tradición literaria del género "diarios de viaje" bajo una visión decimonónica del mundo, diría Humboldt, tan rigurosa como exaltada, próxima a la practicada por otros coetáneos chilenos como Vicuña Mackenna (1856), Barra (1878), Sanhueza (1889), Pérez Cangas (1911), Errázuriz (1947) o Pérez Rosales (1949), entre otros.

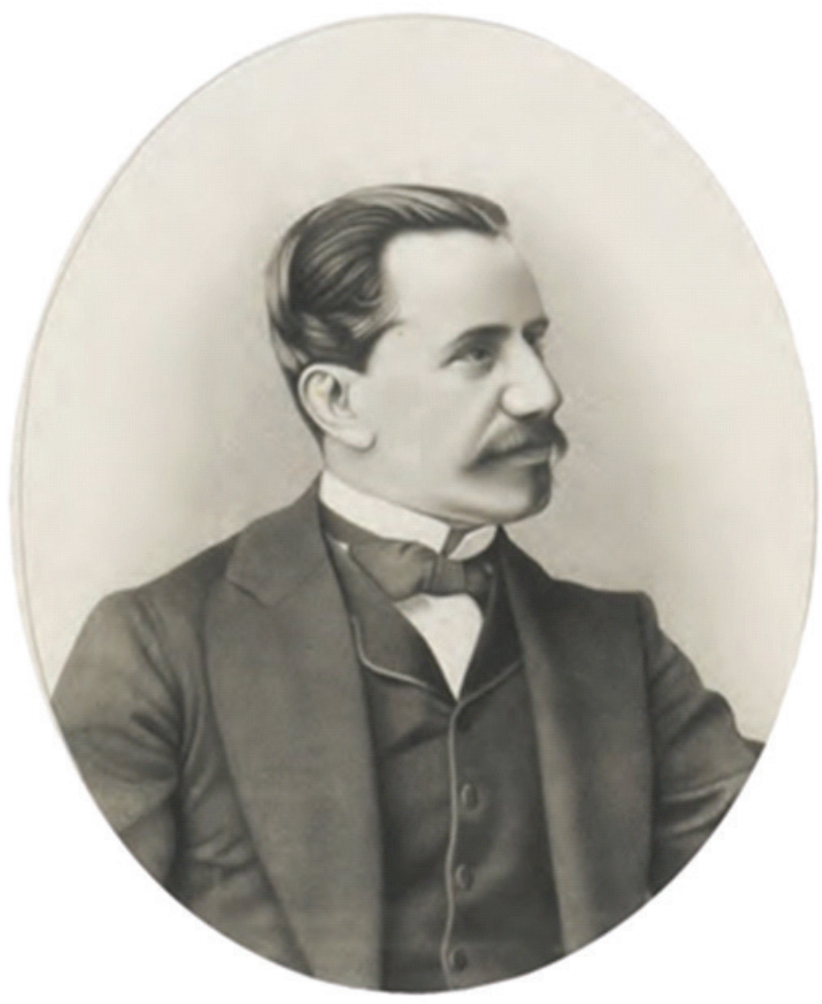

Figura 1. Retrato de Francisco Echaurren dibujado a pluma por Manuel Jesús Zubieta, 1876. Archivo del Museo Histórico Nacional de Chile.

Los diarios de Echaurren son una fábrica de datos históricos y culturales sobre la élite del Chile decimonónico y su "conciencia planetaria" (Pratt, 2010 , p. 44), pero, sobre todo, un dispositivo privilegiado de autorrepresentación desde donde acceder a las nociones que manejó sobre sí mismo y sobre los demás al mediar el contacto prolongado con "otros" geográfica 
y culturalmente lejanos. Permiten observar, como diría Todorov (2007, p. 21), cuán universales llegó a pensar los valores de su propia sociedad.

Para profundizar en lo anterior, nos fijamos como objetivo del análisis ahondar, por un lado, en el perfil social y político de Francisco Echaurren para comprobar el basamento personal y sociocultural de la autoría y, por otro lado, en dos conjuntos de alteridades que se cruzan continuamente en el texto permaneciendo aun así claramente diferenciadas. Nos referimos en primer lugar a quienes otorgó un tratamiento escritural y relacional de copartícipes del viaje, podríamos decir gente de etiqueta y ceremonial (Elias, 1996, p. 107), y en segundo lugar a quienes jugaron para Echaurren, por el contrario, el rol más bien secundario de sujetos presentes en la escena en movimiento, pero carentes del estatus y consideración que concedió a los distinguidos. En este último caso, y sin agotarlos todos, nos centramos en criados y guías.

A nivel metodológico, hemos transcrito los cuadernos de viaje y los hemos abordado mediante codificación temática, categorización y análisis de contenido (Bardin, 2002 y Gibbs, 2007). Hemos contrastado la veracidad de los datos históricos y completado parte de ellos tanto con bibliografía y documentación especializada como con epistolarios y fondos documentales del autor. De estas fuentes primarias han sido especialmente útiles los dos libros de apuntes y el segundo libro de cuentas del aristócrata con información también referente tanto a los trayectos y destinos como a los gastos realizados en y durante los mismos (Echaurren, 1856, s.f.-a y s.f.-b). Finalmente, para el epígrafe sobre el perfil de Francisco Echaurren, especialmente durante su paso por cargos públicos, hemos cotejado la información autobiográfica de sus textos con los fondos históricos de las municipalidades de Santiago y Valparaíso obrantes en el Archivo Nacional Histórico.

\section{LOS DIARIOS: FORMATO Y CONTENIDO}

Los diarios de viaje de Francisco Echaurren se componen de cuatro cuadernos de una colección mayor que, sin embargo, no se conserva completa. El autor debió de escribir más sobre su viaje, dado que el primer diario que se conserva en el Archivo Nacional comienza con una lista de ciudades visitadas en el centro de Europa sin la fecha de registro de dichas notas, que debió de aparecer en la última hoja del cuaderno precedente, mientras que las últimas notas del último diario tratan sobre la estadía de Echaurren 
en Lisboa y su partida hacia Madeira, toda vez que sabemos que regresaría más tarde a la Europa continental, viajaría hasta Rusia para buscar después el Mediterráneo y navegar en 1856 dirección al sudeste asiático hasta alcanzar en 1857 el continente americano por el Pacífico (Echaurren, s.f.-a, pp. 25-26).

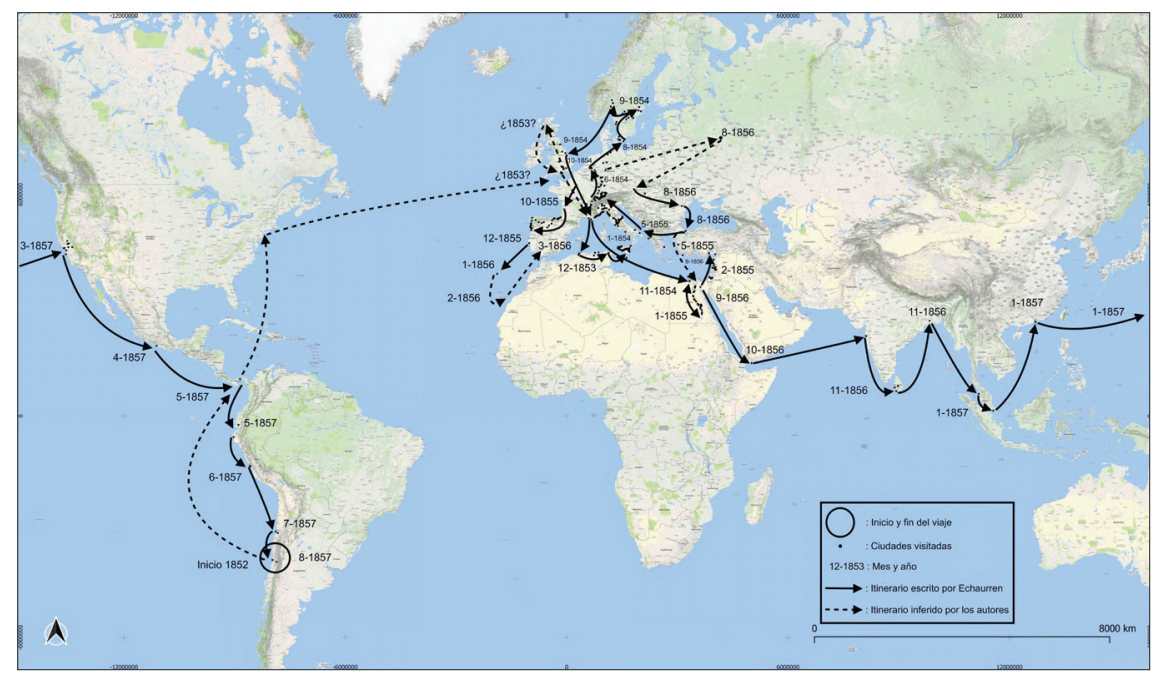

Figura 1. Itinerario del viaje alrededor del mundo de Francisco Echaurren, 1852-1857. Fuente: Echaurren, 1853, 1854a, 1854b, 1855 y s.f.-a, pp. 25-26. Elaboración propia.

Aun así, la evidencia más sólida para pensar en un mayor número de diarios nos lo da el tercero de los cuadernos conservados en orden cronológico, que cuenta en el reverso de su portada con un sello de la marca W. Hammerschmidt de El Cairo, dentro del cual está consignado a lápiz la inscripción " $\mathrm{N}^{\circ} 5$ ". Por ello, Echaurren debió de haber empezado a escribir antes del diario del 53 y haber continuado después del diario del 55.

En lo que se refiere a las características materiales de los diarios, se trata de cuadernos -tres cosidos y uno empastado- cuyas notas manuscritas su propio autor define como "apuntes" (Echaurren, 1854b, p. 126). Pueden clasificarse, por lo tanto, como autodocumentos (Ariztizábal, 2012; Greyerz, 2015) y, en su conjunto, como una bitácora en varios volúmenes de su viaje alrededor del mundo que, sin embargo, no adquiere profundidad de relato por carecer de densidad narrativa, lo que no es óbice para la existen- 
cia de un método y un estilo. Echaurren escribe casi a diario, rara vez deja pasar más de una semana sin continuar con sus apreciaciones, con la excepción de marzo de 1855 en que no escribió nada que se conserve. En cada entrada aporta información de lo vivido y sus coordenadas: fechas, lugares, personas, trayectos y actividades en orden temporal y cronológico. Su estilo es realista, combina un rico vocabulario con rasgos coloquiales como el "ya" en sustitución del etc., y rara vez coquetea con figuras literarias más allá de la comparación o alguna que otra metáfora. Su caligrafía es persistente la mayor parte del tiempo y algo compleja para el lector no avezado en escritura a pluma. La exhaustividad descriptiva y analítica de sus notas no es regular, va evolucionando de una escritura parca en detalles a unos apuntes más completos, reflexivos y críticos conforme acumula experiencia narrativa, incluidos pasajes de humor.

Sus notas tienen, a nuestro parecer, mayor carácter funcional que estético, no siendo incompatibles, por el compromiso con la memoria más que con la expresión. Como decimos, a excepción de contados pasajes en sus últimos diarios, abundan las notas breves, casi telegráficas a veces, con una escritura descuidada más propia de quien redacta como recurso memorístico que del preocupado por terceros lectores. De hecho, cuando escribe para ser leído, como en sus cartas, su estilo es más correcto y depurado. Juan Blest (1877, p. 11) aseguró que la marcada modestia de Echaurren le había impedido siempre dar a conocer dichos apuntes a la opinión pública. Sea como fuere, los apuntes son personales e inéditos.

En lo que se refiere al contenido, la información de los diarios es abundantísima y diversa, si bien prevalece un conjunto de temáticas que nos permite advertir motivaciones constantes durante el viaje. Al autor le interesaron sobremanera los tiempos y distancias de los trayectos, la gestión de lo público y la probidad de los funcionarios, el urbanismo y las infraestructuras, el comercio y el desarrollo industrial, la programación cultural de las urbes que visita, la moral y la higiene públicas, los pertrechos militares, las huellas monumentales de las civilizaciones antiguas, la historia, la religiosidad y la mitología cristianas, la asistencia y el buen servicio en los hospedajes, visitas y travesías y, sin agotar todo el espectro temático, la vida social de las élites políticas, eclesiásticas, diplomáticas, empresariales, etc., de las ciudades por las que pasa. 


\section{ECHAURREN: VIAJERO Y REFORMISTA}

Francisco de Paula Echaurren García-Huidobro vino al mundo en Santiago de Chile el 21 de octubre de 1824 en el seno de una acaudalada familia aristocrática en la que convergieron dos importantes linajes políticos ostentadores de posición, poder y fortuna. Su cuna fue, desde el principio, un privilegiado lugar desde el que observar el mundo y las rentas de sus posesiones los generosos haberes con los que recorrerlo. Su padre, José Gregorio Echaurren, fue diputado y senador de la República y su abuelo materno, Vicente García de Huidobro, fue, antes de la independencia, III marqués de Casa Real, comandante de la Caballería del Príncipe y canciller de la Real Audiencia de Chile. Entroncado en dos dinastías de Estado, liberales por parte de su padre y conservadores por parte de su madre, contó con una educación de élite en el Seminario Conciliar de Santiago, que le permitiría entrar en contacto desde joven con la cultura clásica de Grecia y Roma, como atestiguan sus muchas y detalladas notas sobre el Mediterráneo antiguo en sus apuntes de viaje (Echaurren, 1853, pp. 15-55 y 1854a, pp. 40-65).

En lo que respecta a su vida política, puede considerarse a Echaurren miembro de la generación del 48, en tanto grupo de jóvenes oligarcas influenciados por los valores tardoilustrados del liberalismo burgués y los movimientos revolucionarios de la Primavera de los Pueblos contra el absolutismo y las formas totalitarias de gobierno, muchos de los cuales ocuparían, tras su activa implicación política en el debilitamiento de la República conservadora, responsabilidades de Estado durante la segunda mitad del siglo XIX (Gazmuri, 1999). Iniciaría su andadura política afiliándose al Partido Liberal tras los desmanes conservadores de las elecciones presidenciales de 1846. Más tarde, su apoyo a la fracasada revolución liberal de 1851 lo pondría en el punto de mira de la purga de opositores organizada por el gobierno monttvarista, viéndose obligado a huir al exilio como lo harían, entre otros, José Victorino Lastarria, Francisco Bilbao o Benjamín Vicuña Mackenna. No obstante, Echaurren no se iría para esperar que las aguas se calmasen, volviendo pronto a ocupar la alta posición que sus apellidos le reservaban, sino para "conocer mundo"1, dándole la vuelta completa.

\footnotetext{
${ }^{1}$ Entrecomillamos la expresión por referirnos al sentido que le da Edward Said (1990, p. 54) en el caso de los viajeros occidentales por el norte de África y Oriente durante el siglo XIX, un conocer mundo que suponía elevarse por sobre las contingencias inmediatas de lo cotidiano y alcanzar lo extraño y lejano en una clara demostración además del poder económico necesario para permitírselo.
} 
La vida política de Echaurren cobraría pulso nuevamente con su regreso a Chile en 1857, con 32 años, luego de 4 años y medio de exilio. Su casa llegaría a ser el lugar de encuentro y debate de los liberales santiaguinos, desde donde defendería la Ley de Amnistía rechazada por Montt en 1857. Más tarde, en 1864, entraría en el Parlamento como diputado suplente por Quillota y Limache, destacando en su etapa parlamentaria, por un lado, durante el proceso de reforma constitucional (1864-1865) y, por otro, durante la guerra contra España (1865-1866). Sus dotes para la gestión pública lo llevarían a ser intendente primero de Santiago (1867-1868) y luego de Valparaíso (1870-1876) y entremedio ministro de Guerra y Marina (18681870). Como intendente de la capital, sus proyectos serían fiel reflejo de los intereses temáticos recogidos en sus apuntes y las convicciones pragmáticas maduradas durante su viaje, especialmente en lo referente al orden, la higiene, la enseñanza, la justicia, la probidad, la dinamización de sociedades cívicas y gremiales y la dotación y mejora de infraestructuras para lo que entendió debía ser una ciudad moderna y dinámica (Echaurren, s.f.-b, pp. 1-192).

Al frente de la Intendencia de Valparaíso, su actividad pública, como en Santiago, sería frenética, centrando sus esfuerzos en la modernización y promoción urbanística, la estética, la higiene y la salubridad de la ciudad, la asistencia sanitaria, el orden público, la enseñanza, el comercio, las artes, los festejos y un largo etcétera de medidas transformadoras que contarían no pocas veces con enconadas críticas políticas y personales (Arístides, 1875).

Tanto su espíritu filantrópico como su convicción de que las élites debían participar activamente en el apoyo de causas públicas, le llevaron a convertirse en un destacado benefactor del Chile finisecular, sufragando y/o donando un importante legado patrimonial al Estado. En Santiago, marca aún la hora de la Plaza de Armas el reloj de la torre del Museo Histórico Nacional, entonces sede de la Intendencia, que regalara a la ciudad en $1868^{2}$. Tras su muerte en 1909 , sus diversas colecciones privadas, parte de

\footnotetext{
${ }^{2}$ Dado que por el reloj de la torre de la Intendencia corría el agua de lluvia "a consecuencia del más completo abandono", Echaurren encargó traer desde París la actual maquinaria a través del delegado chileno en la capital francesa, Francisco Fernández, sufragándolo personalmente por "la escasez de los fondos municipales" y donando el inservible a los franciscanos recoletos, que lo habían pedido (Echaurren, s.f.-a, p. 107). Echaurren aprovecharía la remodelación arquitectónica de la Intendencia y el Cabildo, "estudio encargado al arquitecto D. Eusebio Chelli", para instalar el reloj, "el primero que venía a Chile de cuatro esferas y útil de día y de noche", tras reconstruir la torre de la Intendencia (Echaurren, s.f.-b, pp. 158-159).
} 
las cuales adquiriría durante su viaje alrededor del mundo, servirían para crear el Museo de Artes Decorativas de Santiago junto al legado de Hernán Garcés Silva (Museo Nacional de Artes Decorativas, 2015), enriquecer la colección de Artes Decorativas y Escultura del Museo Histórico Nacional, especialmente con piezas orientales, o impulsar, entre otras, la colección de minerales del Museo Nacional de Historia Natural (Machado, 1914). Además de una reseñable colección de arte y una importante biblioteca también donada, su gabinete de curiosidades contaba con los más disímiles objetos de procedencias y periodos dispares, desde armaduras de samuráis a antigüedades egipcias, y de cráneos humanos a álbumes de botánica chilena (Espinosa, 1913; Alegría, Gänger y Polanco, 2009). Con todo, puede que su aportación más valiosa al patrimonio museológico chileno haya sido su colección de monedas y medallas (Valdés, 1960).

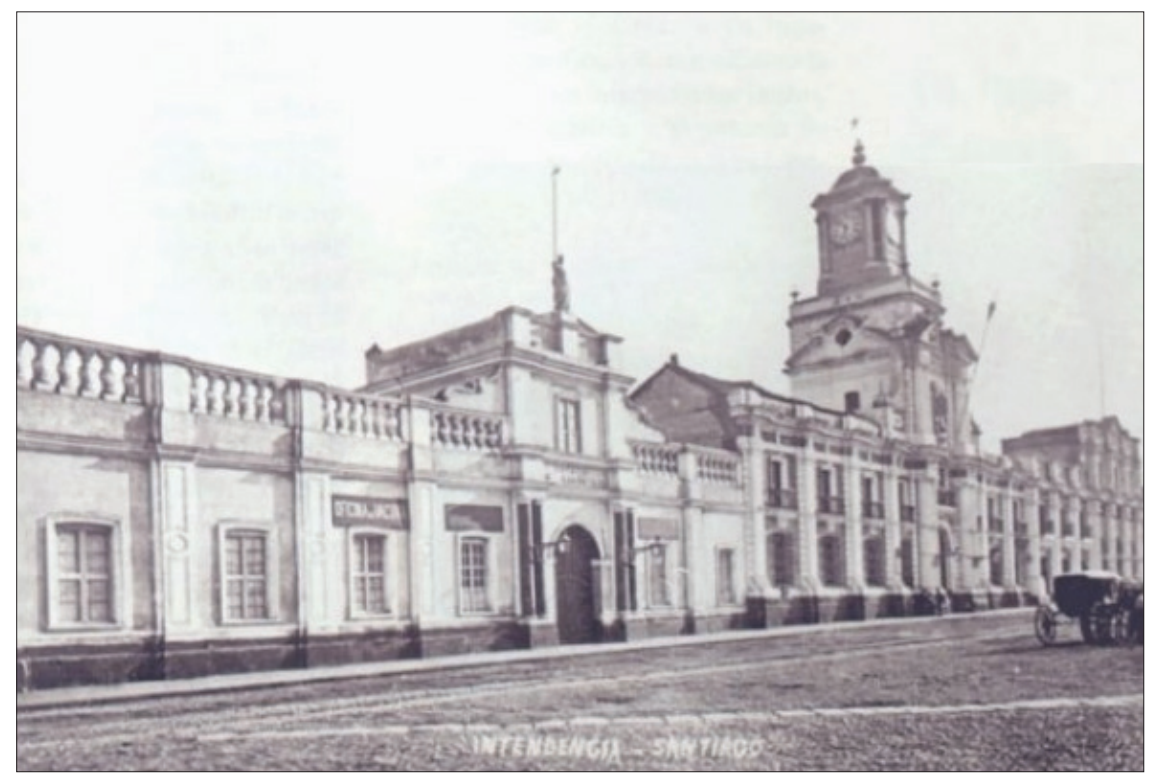

Figura 3. Plaza de Armas de Santiago de Chile con el antiguo Palacio de Gobernadores en primer plano, seguido de la Intendencia de Santiago y finalmente el Cabildo, en torno a 1870, tal y como quedan remodelados durante la gobernación de Francisco Echaurren. Archivo del Museo Histórico Nacional de Chile. 


\section{COMPAÑEROS Y ANFITRIONES: LOS COPARTÍCIPES DEL VIAJE}

En su viaje alrededor del mundo (1852-1857), Echaurren hizo uso de una amplia tipología de alojamientos, generalmente cómodos y caros, como le permitía su pudiente cartera. En grandes ciudades solía preferir hoteles céntricos y de renombre: el Hôtel des Étrangers en París, el de la Ville en Ginebra, el Hôtel d'Angleterre en Copenhague, el de La Croix en Estocolmo, el de Oriente en Alejandría, el Royal de Colombo, el London de Singapur o el Commercial de Hong Kong, entre otros muchos. Cuando la estancia superaba de largo la semana, como fue el caso de su estadía de 20 días en Roma para conocer la ciudad y participar de los oficios vaticanos de la Semana Santa de 1854, prefería el alquiler de apartamentos. En Tierra Santa, los hoteles dejaron paso a las hospederías franciscanas, así como en los trayectos entre las ciudades fueron las posadas las que ofrecerían las mejores posibilidades de un lecho mullido y seco.

Sin embargo, puede que lo que confiera a los diarios de viaje de Echaurren una especial importancia en lo relativo a los hospedajes no sea tanto la distinción de sus alojamientos cuanto la rica información que nos brindan en lo relativo a los círculos sociales que se conformaban en ellos, el perfil social, económico y político de los anfitriones y la tupida red de contactos que se enhebraba gracias a una institucionalizada práctica de presentar a los viajeros mediante cartas de recomendación ${ }^{3}$. Las cartas suponían un ejercicio de construcción y transmisión colectiva del estatus que trasponía al total desconocido en un sujeto de confianza, permitiéndole a renglón seguido transformar dicho estado en el capital social con el que asegurarse un importante número de comodidades: buen recibimiento, buenas atenciones, buena despedida y la fiabilidad de reproducir lo mismo en el siguiente destino (Echaurren, 1853, pp. 6-54 y 1854b, pp. 142-205).

Tanto en los trayectos como en los destinos (véase mapa de su itinerario), Echaurren trababa amistad con quienes podríamos considerar inter pares circunstanciales: hombres singularmente distinguidos en sus entornos, cuyo título, cargo y/o profesión les reportaban un reconocimiento social significativamente elevado, fuesen aristócratas, industriales, comerciantes, banqueros, militares, capitanes de navío, ingenieros, médicos, tratantes de antigüedades, cantantes, pintores, académicos, autoridades locales, clérigos

\footnotetext{
${ }^{3}$ A estas cartas, Echaurren las llama indistintamente "de recomendación" (1853, p. 7), "de subscripción” (1853, p. 18), "de introducción” (1853, p. 19) o "de visita” (1853, p. 35).
} 
o cónsules ${ }^{4}$. De sus ratos con ellos dejó registradas las actividades compartidas y, en muchas ocasiones, los temas de conversación, tan diversos como el comercio del bacalao con un marinero noruego, las campañas militares de los Estados Unidos en México con un general de Nueva Orleans (Echaurren, 1853, p. 5) o los conjuros secretos para controlar las tempestades marinas con los mandos de la fragata Juana de Arco (Echaurren, 1853, p. 5).

Aunque en todo viaje se entra en contacto con una mayor diversidad de personas, son estos a quienes se presenta, con quienes habla, comparte tiempo y primera clase, con quienes visita las ciudades, acude a misa, al teatro, a la ópera o a los casinos, confía su opinión y sus proyectos, pide cartas de recomendación y de quienes se despide, dejando constancia por escrito de sus nombres, apellidos y/o título/cargo/relevancia, como mecanismo de diferenciación, permitiéndonos saber hoy a quiénes consideró copartícipes de su viaje, al contrario de quienes conoció pero anonimizó no considerándolos valedores de quedar individualizados en la memoria de su aventura.

Esta cercanía con representantes de las clases altas de las ciudades por las que paseó le permitió, evidentemente, acceder a espacios exclusivos y selectos como las casas y palacios en que se organizaban las fiestas privadas de la élite local, acontecimientos de los que rara vez sabemos, sino a través de las notas de socialité de la época, tan protocolarias como superficiales. En El Cairo, el 1 de diciembre de 1854, tendría la oportunidad de celebrar el Mawlid al-Nabi al-Sharif (Fiesta del Nacimiento del Profeta) en la casa del sheik o líder religioso de los derviches cariotas junto a Mehmed Said, valí de Egipto y Sudán. Según nos cuenta el autor de las notas, llegarían muy temprano, a las 8 de la mañana. Cuando comienza la fiesta, Echaurren presencia derviches girando hasta quedar "ebrios por sus ceremonias", faquires jugando con sus espadas entre la pericia y la charlatanería, jóvenes tendidos bocabajo en el suelo "para que pasase a caballo sobre ellos el jefe de [los] derviches del Cairo", sacerdotes comiendo serpientes vivas "sin más cubierto ni herramienta que los dientes" mientras hacían "mil ceremonias los otros derviches tocando tamborines, pitos y otros instrumentos del país" en un frenesí desacorde de sones, danzas y "gritos de aquellos fanáticos".

\footnotetext{
${ }^{4}$ No todos los cónsules con los que trató revistieron de la distinción diplomática que hoy les supondríamos. Algunos de los consulados de las ciudades pequeñas a los que recurrió no pasaban de cuartillos con gestiones muy limitadas cuyos cónsules, con escasa formación administrativa, apenas hablaban el idioma del país que representaban. Por ejemplo, cerca de Karnak, en Egipto, Echaurren aseguró que el cónsul británico había sido hasta poco tiempo antes un copto al que habían destituido "por intrigas", sustituyéndolo "un felah borriquero que hablaba poco inglés" (1854b, p. 43).
} 
La mística sufí llevada a ese extremo le parecería una "horrible ceremonia y espectáculo" que, sin embargo, presenciaría durante una hora y media (Echaurren, 1854b, pp. 5-7), probablemente consciente de lo que Norbert Elias (1996, p. 159) definiría como oportunidades de prestigio, sin llegar, no obstante, a convertirse en el exota absorto que describiría en sus ensayos Víctor Segalen (1978, p. 29).

Esta posibilidad de acceder a los círculos sociales de las clases dominantes $\mathrm{y}$, en muchas ocasiones, a sus hogares, pusieron a menudo a Echaurren frente a comportamientos o actitudes que consideró reprobables. En los cuadernos de viaje, en este sentido, la palabra no es solo recuerdo o reconocimiento, sino también reproche, juicio y acusación. Podemos comprobarlo de forma clara en los comentarios en que aborda lo que, en su época, eran consideradas desviaciones morales, como las expresiones sexuales desviadas del fin procreativo y el orden matrimonial. Ello nos permite saber tanto sobre los esquemas valóricos del autor cuanto sobre la poderosa atracción por descubrir el mundo íntimo de los demás (Foucault [1976] 2007, pp. 9-21), desvelándonos además la diversidad de expresiones amatorias, experiencias conyugales y orientaciones afectivo-sexuales presentes entre las élites con las que alternó. De lo anterior, Echaurren destacaría la promiscuidad, el concubinato, el adulterio, la bigamia, la prostitución, el ménage à trois y la homosexualidad. Por ejemplo, de un lord inglés afincado en la ciudad de Túnez anotó brevemente "su inmoralidad [y] sus mujeres" (Echaurren, 1853, pp. 12). Con algo más de detalle cargaría contra la máxima autoridad del país tunecino por la "decrepitud e inmoralidad del Bey [Ahmed I] [y] sus muchachos, [con] carencia de herederos" (Echaurren, 1853, pp. 12). De Federico VII de Dinamarca criticaría su "inmoralidad" al haberse separado "sucesivamente" de sus dos esposas anteriores para terminar juntándose con la última "que hoy tiene, una modista bailarina del teatro y prostituta", a quien "tomó por mujer en circunstancias que hacía de querida de un impresor, el que por este motivo vive hoy en palacio y va a medias con el rey" (Echaurren, 1853, pp. 76-77). Del conservador de las ruinas de Tebas, Henri Maúnier, dejó constancia que "venido de Francia, donde tenía una mujer e hijos y no fortuna", había tenido la suerte de ser bien acogido tanto por el gobierno egipcio como por algunos particulares. A uno de ellos "Maúnier había respondido [haciendo] uso de la esposa de su buen hospedador" concluyendo "por arrancarla de su esposo [y] habitando hoy día en Luxor con ella como si fuera su legítima esposa" (Echaurren, 1854b, pp. 61-63). Más adelante, ya en Tierra Santa, del Patriarca Latino de Jerusalén, Giuseppe Valerga, diría que su actitud "no parece muy 
propia, se conoce que sus maneras de presentarse en público son afectadas [y] parece que se ocupa mucho de su larga barba y sus vestidos" (Echaurren, 1854b, p. 209).

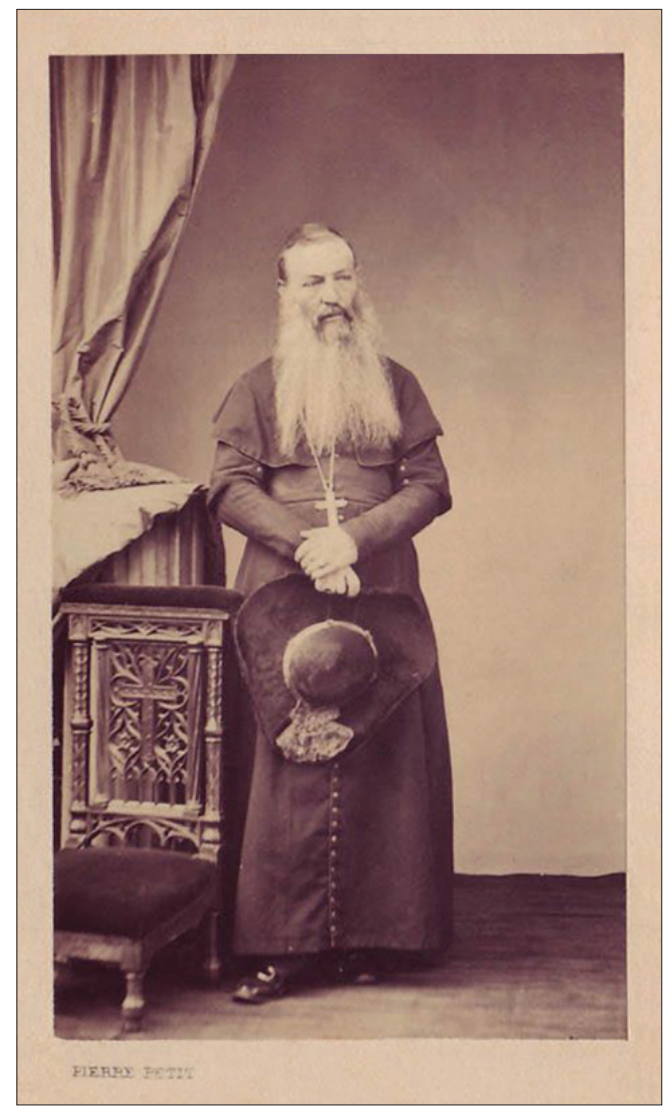

Figura 4. Monseñor Giuseppe Valerga, 1869. Fotografía de Pièrre Petit. Fuente: Luminous-Lint Collection.

\section{CRIADOS Y GUÍAS: LOS IMPRESCINDIBLES MINIMIZADOS}

El viaje aristocrático o de élite era un viaje en compañía y no solo de rostros con títulos nobiliarios o destacados cargos militares o eclesiásticos. Los baúles necesitaban porteadores, las compras braceros y las gestiones secretarios. Los adinerados viajeros del siglo XIX iban acompañados de su 
propio servicio. Echaurren tuvo al menos dos criados, Gustavo y Charles; si bien es solo el primero quien lo acompaña en el trayecto por Europa, el norte de África y Próximo Oriente, del que dan cuenta los diarios conservados. De Gustavo no sabemos sus apellidos, porque el autor de los textos no lo recogió en ningún momento ${ }^{5}$. En los apuntes, Gustavo aparece siempre tratado como personal de servicio, en un segundo plano. Tanto es así que Echaurren no solía comer junto a él (Echaurren, s.f.-b, pp. 2 y 3). El criado se transforma en una necesidad más que en un acompañante, en fuerza de trabajo más que sujeto fundamental para el viaje.

Del mismo modo, al resto de quienes le sirvieron como cargadores en los puertos, cocheros durante los trayectos o mozos y doncellas en los hoteles de postín los llama por su oficio, no por su nombre. Nunca aparecen valorados y contaron con el reproche de no encajar en los cánones del empleado atento a un viajero acostumbrado a la comodidad y al trato exquisito, al confort y a la pleitesía. En su viaje por Inglaterra en 1854, Echaurren se quejaría, por ejemplo, de que en el hotel de York en que se hospedaba no le dejaban fumar, que el olfato de las mucamas era insorteable, que las comidas eran malas y caras, que en el establecimiento no se hablaba más que inglés, lo que creía una "estupidez", pues dejaba a clientes como él invalidados para ordenar convenientemente a los criados que no se tomaban mucha molestia en "entender o darse a entender" y a quienes al preguntar, si contestaban lo hacían "evasivamente a fin de nunca satisfacer". La irritación que le produjo dicha experiencia terminaría por hacerle extender la crítica a media Gran Bretaña, asegurando de los súbditos ingleses que la "descortesía y la impolítica" eran su principal "distintivo" (Echaurren, 1853, p. 27).

Para Echaurren, los trabajadores, esos actores secundarios del viaje en cuyo ancho espectro cabían sin distingos botones de hotel o revisores ferroviarios, debían cumplir el cometido doble de producir y agradar, criados, al fin y al cabo. En el tratamiento escritural del texto, el autor fija así el clasismo normalizado que practica en su vida diaria.

Relativo a los guías, la incursión de Echaurren por el Nilo nos ha dejado otro importante conjunto de notas que nos permiten profundizar más aún en los diversos modelos de orden y dependencia de los viajeros de la élite social y sus asistentes. En noviembre de 1854, Echaurren contrataría en Alejandría un dragomán -guía e intérprete- que le permitiría viajar por

\footnotetext{
${ }^{5}$ De Charles, que trabajaría para Echaurren cuatro meses, de abril a julio de 1857, sabemos que se apellidaba "de Buy" porque lo consignó - una sola vez- en su Libro segundo de cuentas (1856, p. 22).
} 
la tierra de los faraones cumpliendo con la aspiración de un pequeño pero creciente número de aristócratas, burgueses e intelectuales de conocer in situ el pasado egipcio apenas 30 años después de que Jean François Champollion diera inicio a la moderna egiptología con el desciframiento de los jeroglíficos.

El papel del dragomán era asegurarles llegar a los yacimientos egipcios, empresa que en solitario era prácticamente imposible de lograr para estos viajeros occidentales, la mayor parte de ellos desconocedores del país, sus gentes, costumbres y lenguas. Probablemente por ello Echaurren no trataría a su dragomán como a un criado más sino como a un conseguidor imprescindible de las experiencias que buscaba a ambas orillas del Nilo. Georgio Demetrio 6 , su dragomán, le amortiguaría así el extrañamiento cultural de un escenario social cognoscitivamente distante, al tiempo que desentrañándole la realidad contemporánea de una sociedad, la egipcia, étnica y religiosamente diversa, además de sofocada por ambiciones imperiales: ocupada por los otomanos, deseada por británicos y franceses, y partícipe a la fuerza en la Guerra de Crimea.

Bajo estas coordenadas resulta más esclarecedor leer en los apuntes de Echaurren cómo en Benimef, nuestro viajero recordaría visitar "algunas casernas de caballería donde encontramos a las puertas multitud de mujeres que tenían como un canto", que no era sino una letanía penosa de lamentos "por [los] hijos o maridos que les habían tomado para soldados". Llega a tal conclusión por intermediación del dragomán, que le explica que "se tiran [de] los cabellos, se rompen los vestidos [y] se echan polvo sobre la cara" porque "dicen que muerto[s] al menos pueden visitar su[s] sepulcro[s]" (Echaurren, 1854a, p. 8). El dragomán le permite a Echaurren acceder al plano de los significados de las prácticas y no solo de su escenificación, traduciendo aquella caterva de mujeres dolientes a las puertas de un cuartel en madres y esposas, corporizando la desesperanza de saber que el reclutamiento de sus parientes era sinónimo de su muerte segura y de un duelo sin cadáver ni sepultura.

Ello no suponía, conviene aclarar, que el rol del dragomán como traductor cultural lograra o alentara la empatía. Los cuadernos de Echaurren cuentan con pasajes que muestran una gran resistencia a observar en los

\footnotetext{
${ }^{6}$ Por el semanario canadiense The British Columbian sabemos que Georgio Demetrio era griego, médico y el occidental que relató a las autoridades británicas los detalles de la muerte del general Charles George Gordon el 26 de enero de 1855, tras la caída de Jartum a manos de las tropas del mahdi Mohammed Ahmed (Late Canadian News, 30 de enero de 1889, p. 8).
} 
lugareños pobres algo más que un estorbo. Podemos asegurar que para Echaurren la convergencia en los yacimientos arqueológicos del pasado idealizado y del presente marginalizado no supusieron la más feliz de las imbricaciones. Por lo general, al autor le disgustaba la presencia de la población local entre las ruinas egipcias. Sentía antipatía por los pobres, que para él ensuciaban, afeaban y malograban aquel patrimonio invaluable. En su texto, son gente inculta y supersticiosa que dificultaba el viaje, alejados de los patrones civilizados de cultura.

\section{CONCLUSIONES}

Los cuadernos de viaje de Francisco Echaurren son piezas escriturales de marcado interés para comprender las formas de subjetividad y construcción de la alteridad de la élite chilena en sus largos viajes, como el deseo de conocer espacios recónditos del mundo -bajo imaginarios donde conocimiento, aventura y exotismo van de la mano- o el trato dispensado a cada sujeto en virtud de su lugar en la división social de clases, con los grupos burgueses, aristocráticos e ilustrados como referentes fundamentales de la consideración escritural. Y lo anterior no cobra valor solo por tratarse de los más antiguos cuadernos conservados del viaje de un chileno alrededor del mundo, sino por la franqueza de una intimidad asegurada por el carácter personal y privado del texto, liberado -hasta donde es posible culturalmente- de las contenciones y acomodos propios de los escritos hilvanados bajo la consciencia del futuro juicio de la opinión pública. Su coetáneo Vicuña Mackenna (1856, p. I) confesaría en el prefacio de la publicación de sus diarios de viaje haber tenido que enfrentar dicha coerción al redactar sus notas precisamente con la intención de ser publicadas.

Los diarios muestran un empeño constante por exponer la diferencia con los distintos y acortar la distancia con los iguales, en una representación rígida de un mundo dividido en clases. Y Echaurren lo hizo esforzándose por evitar la debilitación de sus referentes identitarios, como si estos no fueran dúctiles y proclives al cambio. Así, marcaría constantemente sus formantes de élite liberal en el comercio y conservadora en el trato: hizo ostentación económica al tiempo que refunfuñó cada limosna, viajó con criado, en cada lugar se rodeó de quienes mandaban o eran admirados, trató como copartícipes de viaje a señalados por el cargo, la valentía o el honor, cumplió con celo sus obligaciones religiosas, distanciándose de todo credo alejado de la fe católica, admiró el patrimonio monumental y las ruinas 
civilizatorias, pero afeó a cuantos encontró cobijados en ellas como forma humilde de proveerse de techo.

Sus páginas condensan los presupuestos de libertad individual y experiencia vivencial sobre los que se sostiene el edificio de la modernidad que hoy, avanzada, atraviesa globalmente la cultura occidental, con una atracción ya marcada por el anhelo de experiencias únicas. Para ello, invirtió parte de su fortuna en un viaje incierto, de destinos y tiempos decididos por tramos y no carente de dificultades y peligros pero en el que supo, no obstante, abrirse las puertas de los círculos más selectos y experimentar los logos más desconocidos sin que dejara una sola vez por escrito la más mínima insinuación de haberse arrepentido de embarcarse en tal periplo.

\section{REFERENCIAS}

Alegría, L.; Gänger, S. y Polanco, G. (2009). Momias, cráneos y caníbales. Lo indígena en las políticas de "exhibición" del Estado chileno a fines del siglo XIX. Nuevo Mundo Mundos Nuevos [en línea]. Recuperado de: http://nuevomundo.revues.org/53063

Arístides (pseudónimo) (1875). El candidato a sultán. Folleto de actualidad. Valparaíso, Chile: Imprenta de La Patria.

Aristizábal, C. (2012). Autodocumentos hispanoamericanos del siglo XIX. Fuentes personales y análisis histórico. Berlín, Alemania: Lit Verlag.

Bardin, L. (2002). Análisis de contenido. Madrid, España: Akal.

Barra, M. de la (1878). Mis impresiones y mis vicisitudes en mi viaje á Europa pasando por el Estrecho de Magallanes... Buenos Aires, Argentina: Piqueras Cuspinera y Ca.

Blest, J. (1877). Don Francisco Echaurren Huidobro. Apuntaciones biográficas. Valparaíso, Chile: Imprenta del Universo de G. Helfmann.

Brintrup, L. (1992). Viaje y escritura: viajeros románticos chilenos. Nueva York, Estados Unidos: American University Press.

DIBAM (2016). Resolución Exenta 1279 de 14 de noviembre de 2016 para el contrato de compraventa de documentación patrimonial. Santiago, Chile: Dirección de Bibliotecas, Archivos y Museos de Chile.

Echaurren, F. (1853). C. Bern. 2. [Diario de viaje manuscrito inédito]. Colección Francisco Echaurren. Archivo Nacional Histórico de Chile.

Echaurren, F. (1854a). Agosto 25 1854. [Diario de viaje manuscrito inédito]. Colección Francisco Echaurren. Archivo Nacional Histórico de Chile.

Echaurren, F. (1854b). Nobre 19-1854. [Diario de viaje manuscrito inédito]. Colección Francisco Echaurren. Archivo Nacional Histórico de Chile.

Echaurren, F. (1855). Memorias Francisco Echaurren 1855. [Diario de viaje manuscrito]. Colección Francisco Echaurren. Archivo Nacional Histórico de Chile. 
Echaurren, F. (1856). Libro segundo de cuentas. [Cuaderno manuscrito inédito de apuntes contables]. Colección Francisco Echaurren. Archivo Nacional Histórico de Chile.

Echaurren, F. (Sin fecha -a). Tomo $1^{\circ}$. [Cuaderno manuscrito inédito de apuntes memorialistas]. Colección Francisco Echaurren. Archivo Nacional Histórico de Chile.

Echaurren, F. (Sin fecha -b). Libro $2^{\circ}$. [Cuaderno manuscrito inédito de apuntes memorialistas]. Colección Francisco Echaurren. Archivo Nacional Histórico de Chile.

Elias, N. (1996). La sociedad cortesana. Ciudad de México, México: Fondo de Cultura Económica.

Errázuriz, I. (1947). Diario de don Isidoro Errázuriz. Santiago, Chile: Sociedad de Bibliófilos de Chile.

Espinosa, M. (1913). Informe del jefe de la sección de plantas criptógamas. Boletín del Museo Nacional, 5(1), 235-237.

Foucault, M. ([1976] 2007). Historia de la sexualidad I. La voluntad del saber (31 a edic.). Ciudad de México, México: Siglo XXI Editores.

Gazmuri, C. (1999). El "48" chileno. Igualitarios, reformistas, radicales, masones $y$ bomberos. Santiago, Chile: Editorial Universitaria.

Gibbs, G. (2007). Analyzing Qualitative Data. Londres, Reino Unido: SAGE.

Greyerz, K. von (2015). Observations on the Historiographical Status of Research on Self-Writing. En Ulbrich, C.; Greyerz, K. von y Heiligensetzer, L. (eds.). Mapping the "I". Research on Self-Narratives in Germany and Switzerland (pp. 34-57). Leiden, Holanda: Brill.

Late Canadian News (30 de enero de 1889). The British Columbian, 34, 5, 8.

Machado, M. (1914). Informe del jefe de la sección de jeologia. Boletín del Museo Nacional, 7(1), 241-244.

Maino, V. (2014). Testimonios del Yo. Memorias, Autobiografía, Recuerdos. Santiago, Chile: Origo Ediciones.

Museo Nacional de Artes Decorativas de Chile (2015). Historia. Santiago, Chile: Servicio Nacional de Patrimonio Cultural.

Pérez Cangas, E. (1911). De Chile á Europa. Santiago, Chile: Imp. Victoria.

Pérez Rosales, V. (1949). Diario de un viaje a California. 1848-1849. Santiago, Chile: Sociedad de Bibliófilos de Chile.

Pinto, J. (2008). Proyectos de la élite chilena del siglo XIX. Alpha, 26, 167-189.

Pratt, M. (2010). Ojos imperiales. Literatura de viajes y transculturación. Ciudad de México, México: Fondo de Cultura Económica.

Ramírez, V. (2014). Ficción y creación del mundo oriental en relatos de viajeros chilenos del siglo XIX. Tesis Doctoral. Santiago, Chile: Universidad de Chile.

Said, E. (1990). Orientalismo. Madrid, España: Libertarias.

Sanhueza, R. 1889. Viaje en España (vols. 1 y 2). París, Francia: Librería de Garnier Hermanos.

Segalen, V. (1978). Essai sur l'exotisme (1904-1918). Montpellier, Francia: Fata Morgana. 
Todorov, T. (2007). Nosotros y los otros. Reflexión sobre la diversidad humana. Ciudad de México, México: Siglo XXI Editores.

Valdés, S. (1960). El arte de la moneda. Santiago, Chile: El Diario Ilustrado.

Vicuña Mackenna, B. (1856). Pájinas de mi diario durante tres años de viajes: 1853-1854-1855. Santiago, Chile: Imprenta del Ferrocarril. 